\title{
Avaliaçáo da aprendizagem no Ensino Superior: perspectivas críticas ou técnicas?
}

\author{
Patrícia Magalhães Pinheiro* \\ Rafaella Rodrigues Santos**
}

\section{Resumo}

Este artigo aborda as concepçóes de professores sobre a avaliação da aprendizagem no Ensino Superior e as práticas avaliativas que eles têm utilizado em suas aulas, bem como uma contraposição das concepçôes dos seus alunos com sua visão sobre o tema. Por meio de questionários, numa abordagem qualitativa, buscamos apontar as diferentes concepções que emergem do universo de cinco professores e 48 alunos, do curso de Ciências Biológicas, da Universidade Federal de Goiás. Apesar de percebermos grande recorrência da avaliação da aprendizagem como verificação e medição de conhecimentos, notamos também que concepções mais críticas em relação ao tema, pouco a pouco, são construídas nesse universo educativo, o que nos demonstra certo avanço em relação às práticas pedagógicas dos professores e, consequentemente, uma formação mais crítica dos alunos.

Palavras-chave: avaliação da aprendizagem, práticas pedagógicas, ensino e aprendizagem.

\section{Assessment of learning in higher education: a critical or technical perspective?}

\begin{abstract}
This article discusses teachers' conceptions of assessment of learning in higher education and the assessment practices used in their classes, and contrasts them with students' views on the subject. Through questionnaires, with a qualitative approach, we point out the different conceptions that emerge from the world of 5 lecturers and 48 students, on the Biological Sciences Course at the Universidade Federal de Goiás. Although there is a great recurrence of the assessment of learning as the checking and measuring of knowledge, it was also seen that more critical conceptions are being constructed little by little in relation to the subject in this educational universe, which shows certain progress in relation to lecturers' pedagogical practices and consequently a more critical formation of students.
\end{abstract}

Keywords: assessment of learning, teaching practices, teaching/learning.

* Mestranda em Educação em Ciências e Matemática, Universidade Federal de Goiás. E-mail: patti_ magalhães@hotmail.com

** Mestranda em Educação em Ciências e Matemática, Universidade Federal de Goiás. E-mail: rafaellarodrigues.bio@hotmail.com 


\section{Introdução}

Existem várias vertentes que se referem à concepção das práticas de avaliação escolar, isto é, são diversos os campos que tentam problematizar este tema. Neste artigo, a avaliaçáo escolar é tratada como processual e contínua; ela exige um exercício de profundo conhecimento do aluno, do professor, do contexto e da relaçáo desses sujeitos com a realidade em que estáo inseridos. Nesse sentido, entende-se a avaliação como "reveladora das possibilidades de construçáo de um processo educativo mais rico e mais dinâmico" (DALBEN, 2002).

Por muito tempo, a avaliação escolar estava ligada ao rendimento escolar do aluno e aos resultados da aprendizagem e, dessa forma, era reduzida a uma concepção baseada na quantificação do conhecimento através dos resultados das provas ou dos testes. Infelizmente, nota-se que essa é uma concepção de avaliação ainda predominante, prevalecendo muitas vezes na prática de inúmeros professores, o que retrata uma necessidade de controle, de poder e representa uma sociedade nada democrática e amplificadora das desigualdades sociais.

Mesmo sendo conceito - avaliaçáo - e designaçáo de sua ação avaliação educacional - permeada de vários sentidos, e suportando várias concepçóes e opiniōes elaboradas por diferentes autores, prevalece na prática, levada a efeito no ambiente escolar, a avaliação educacional baseada na verificaçáo (provas, testes, trabalhos) do rendimento do aluno fundada na necessidade de controle externo da aprendizagem. (ANDRADE, 2003, p. 41)

Perante essa situação, os professores vivem em um constante conflito advindo das "regras burocráticas" geradas na escola justamente por essa organização ser baseada no controle do saber. Nesse sentido, deve-se destacar a importância de os professores buscarem métodos avaliativos diversificados que propiciem um maior conhecimento do seu aluno, além de procurar entender que a avaliação deve ser vista como parte integrante do processo de ensino e aprendizagem e não como a finalização de conteúdos estudados.

Em contrapartida, devemos lembrar que existem diversos fatores que impedem os docentes de realizarem essas práticas avaliativas diferenciadas, como a concepçáo da escola, a demanda de alunos por classe e a falta de discussão sobre o assunto no espaço escolar. 


\begin{abstract}
Mas [os professores] reconhecem as dificuldades apresentadas pela organização da escola e pelo número excessivo de alunos em classe como fatores, provavelmente, intransponíveis para o estabelecimento de processos mais adequados de avaliação. Sabem que medir a aprendizagem apenas por meio de provas ajuda pouco e que discutir avaliação significa discutir a aprendizagem, o ensino, o currículo, o projeto pedagógico da escola, o sistema da escola, a formação dos professores e as políticas educacionais de forma geral. (DALBEN, 2002, p. 16)
\end{abstract}

Os estudos e as discussóes presentes em torno desse tema nos evidenciam uma concepção de avaliação da aprendizagem com uma perspectiva mais crítica, transformadora da atual realidade vigente e como possibilidade de uma nova concepção de educação. Nesse sentido, arraigadas à concepção de avaliação estão os objetivos da educação e, com isso, a expressão do desejo de se formar sujeitos críticos ou náo. Para que se formem sujeitos autônomos, é de suma importância tratar a avaliação da aprendizagem como uma atividade contínua, participante de todo o processo de aprendizagem.

Numa abordagem crítica, a avaliaçáo centra-se nos processos e evolui de acordo com as transformaçóes do contexto. Mais do que medir, avaliar significa entender, analisar, rever e refletir, pois educação e avaliação não podem ser vistas como processos tecnicistas, desligados de valores. (CHAVES, 2003, p. 41)

Assim, vale lembrar que a avaliação assume um papel de facilitadora do processo de construção de conhecimentos e de crescimento pessoal tanto para o professor quanto para o aluno, constituindo o momento em que é possível haver uma troca de ideias e de valorização do conhecimento prévio de cada indivíduo. A avaliaçáo deve ser entendida como parte do processo educativo sem assumir um papel técnico de medição dos conhecimentos adquiridos.

A avaliaçấo, diferentemente da verificação, envolve um ato que ultrapassa a obtenção de configuração do objeto, exigindo decisão do que fazer ante ou com ele. A verificação é uma ação que "congela" o objeto; a avaliação, por sua vez, direciona o objeto numa trilha dinâmica de ação. (LUCKESI, 1995, p. 43)

Sob esse olhar, este texto tem como objetivo analisar as diversas concepçóes de professores do Ensino Superior em relação à avaliação da aprendizagem, bem como evidenciar suas práticas avaliativas. Pretende-se 
também contrapor o discurso dos professores sobre este tema com a visão dos alunos, dando voz aos discentes, já que estes são os protagonistas nesse processo.

\section{A pesquisa}

Esta pesquisa é de cunho qualitativo e, portanto, leva em consideração as múltiplas variáveis do objeto. De acordo com Fraser e Gondim (2004), a "abordagem qualitativa ou idiográfica parte da premissa de que a ação humana tem sempre um significado (subjetivo ou intersubjetivo) que não pode ser apreendido somente do ponto de vista quantitativo e objetivo".

Esse tipo de pesquisa acontece em contraposição às abordagens que defendem a quantificação e o controle rígido das variáveis em busca de um conhecimento objetivo.

A pesquisa qualitativa costuma ser direcionada, ao longo de seu desenvolvimento; além disso, busca enumerar ou medir eventos e, geralmente, não emprega instrumental estatístico para a análise dos dados; seu foco de interesse é amplo e parte de uma perspectiva diferenciada da adotada pelos métodos quantitativos. (NEVES, 1996, p. 1)

Para a construção dos dados, utilizamos de questionários definidos pelo conjunto de perguntas sobre um determinado tópico que náo testa a habilidade do respondente, mas mede sua opinião, seus interesses, os aspectos de personalidade e as informaçóes biográficas (YAREMKO, HARARI, HARRISON e LYNN, 1986). Estes questionários de pesquisa devem ser corretamente interpretados pelo público questionado/pesquisado; ser preenchidos corretamente; ter retorno maciço; ser de fácil tabulação; atingir determinado público-alvo; ter critérios para a amostragem; motivar seu preenchimento; ser planejado. Tomando esses cuidados na elaboração, distribuição e análise de dados, o questionário se torna um aliado às pesquisas no âmbito educacional.

Para esta investigação, foi elaborado um questionário com perguntas de múltipla escolha e perguntas abertas. As perguntas de múltipla escolha nos permite obter respostas específicas, de fáceis respostas e tabulaçóes, mas não permitem o uso da criatividade ou originalidade. Já as perguntas abertas nos permitem medir a organização de ideias, gerar informaçóes imprevisíveis, porém requerem muito tempo e esforço do entrevistado na 
hora de responder e muito tempo do pesquisador na hora da codificação e tabulação dos dados. As respostas obtidas por meio da aplicação dos questionários são analisadas e discutidas à luz de teorias que envolvem a avaliação da aprendizagem.

Com o intuito de evidenciar as diferentes visóes dos professores das áreas puras e das áreas educacionais, bem como entre os professores e os alunos sobre os processos avaliativos no Ensino Superior, foram escolhidos, para esta investigaçáo, os docentes e discentes do curso de Ciências Biológicas, da Universidade Federal de Goiás.

Dessa forma, os professores e seus alunos escolhidos para responderem aos questionários foram dois da área educacional, que lecionam as disciplinas de Estágio Curricular Supervisionado I e II, Ensino de Ciências no Ensino Fundamental e Ensino de Biologia no Ensino Médio e três das áreas específicas (puras), que lecionam as disciplinas de Genética e suas especificidades, Biogeografia, Sistemática e Zoologia.

É importante destacar que os professores da área pura são identificados aqui como (PP) e numerados de um a três. Os professores da área educacional estão identificados como (PE) e numerados de um a dois. Os alunos dos professores da área pura foram identificados como (AP) e numerados de 1 a 24 . Os discentes dos professores da área educacional também foram identificados como (AE), e também numerados de 1 a 24 .

Os alunos dos professores da área educacional perfizeram um total de 24 questionários, já os professores das áreas específicas somaram 95. Essa diferença numérica está ligada ao fato de os professores das áreas específicas ministrarem disciplinas chamadas núcleos comuns, ou seja, tanto a licenciatura quanto o bacharelado cursam essas disciplinas; portanto, o número de alunos é maior. Já os professores da área educacional ministram disciplinas apenas para alunos da licenciatura, justificando o seu número reduzido.

Para que houvesse uma harmonia entre a quantidade dos sujeitos entrevistados, optamos por igualar o universo de alunos - tanto da área educacional (universo de 24 alunos) quanto da área pura (universo de 95 alunos) - utilizando $25 \%$ dos questionários referentes aos alunos entrevistados pelos professores (área pura), totalizando 24 questionários respondidos para cada área. Sobre esse assunto, Carvalho (2006) afirma que "uma amostra é considerada representativa quando ela apresenta as mesmas características gerais da população da qual foi extraída”. Ainda sobre a 
amostragem, Minayo (1999) nos lembra que "pode ser considerada uma amostra ideal aquela que reflete as múltiplas dimensóes do objeto de estudo. A amostragem boa é, portanto, aquela que possibilita abranger a totalidade do problema investigado em suas múltiplas definiçōes".

\section{Análise dos dados}

A análise dos dados permitiu a construção destas três categorias que respondem à nossa problemática, elas emergem, a posteriori, a partir dos dados constituídos: 1- Compreensão da avaliação da aprendizagem; 2- Papel da avaliação no processo de ensino e aprendizagem; 3- Instrumentos utilizados na avaliação da aprendizagem.

\section{Categoria 1: Compreensão da avaliação da aprendizagem}

Esta categoria nos permite entender quais concepçóes sobre a avaliação da aprendizagem acompanham professores e alunos, visto que são construídas ao longo da formação, das vivências e reflexôes em torno do tema.

Uma das concepçóes que emergiu refere-se à avaliação da aprendizagem como um método de aferição e verificação de capacidades e competências dos alunos, de cumprimento de objetivos propostos pelos professores, de compreensão e assimilação de conteúdos ministrados e da eficácia do método utilizado. É importante explicitar que essa concepção foi a mais recorrente dentre os professores da área pura e que nenhum dos professores entrevistados da área educacional corrobora com essa concepçáo. Portanto, esses professores possuem uma clara concepção de avaliação baseada na dimensão técnica, que está intimamente ligada ao entendimento desta como simples mediçáo. Destacamos alguns depoimentos:

PP1: Tentativa de verificar como os alunos compreenderam e assimilaram o conteúdo dado em aula.

PP2: Uma estratégia para verificar se os objetivos estabelecidos para a disciplina, curso ou nivel de estudo foram atingidos.

Outra concepção evidenciada e destacada pelos professores da área educacional foi a da avaliação como componente indissociável do processo de ensino e aprendizagem, o que demonstra uma perspectiva mais crítica em 
relação ao tema. Essa concepção leva em conta o contexto em que professor, aluno e comunidade estão inseridos, o (re)planejamento e redirecionamento das práticas pedagógicas do professor nas aulas.

PE1: A contextualização é levada em consideração no momento de elaboração do plano de ensino. Como é qualitativa e não só quantitativa pode considerar os saberes construidos fora do contexto escolar.

PE2: Entendo avaliação como um processo de acompanhamento do processo de ensino e aprendizagem.

Entendemos que essa perspectiva de avaliaçáo evidencia uma mudança de postura filosófica e teórica por parte do professor, além de entender a avaliação como parte do processo da atividade educativa e náo como produto final.

Ao analisar os questionários dos alunos, notamos convergências das suas concepçôes de avaliação da aprendizagem com a dos professores. Há docentes que concordam com a ideia de avaliação como aferição e verificaçáo, e outros entendem a avaliação como indissociável do processo de ensino e aprendizagem. Nesse sentido, os alunos concordam, na maioria das vezes, com as opinióes de seus professores.

AP18: Verificar se houve ou não aprendizado através das atividades e testes.

AP20: Processo importante para avaliar os alunos e para avaliar se as metodologias utilizadas durante o processo de ensino e aprendizagem têm sido eficazes para se cumprir um objetivo.

AE6: $E$ um teste que visa quantificar o conhecimento do aluno.

AE22: A avaliação da aprendizagem escolar faz parte de um processo em que seu papel é mostrar a realidade da vivência escolar.

\section{Categoria 2: Papel da avaliaçáo no processo de ensino e aprendizagem}

Esta categoria evidencia a compreensão dos professores e alunos em relaçáo à função assumida pela avaliação no processo educativo, além de explicitar as angústias e dificuldades dos professores relacionadas a esse tema.

Quanto ao papel assumido pela avaliação, os professores da área pura acreditam que a avaliação é uma forma de identificar a capacidade e o empenho dos alunos, além de verificar a eficiência do método de ensino aplicado. Acreditam também que é uma forma de redirecionar sua prática pedagógica, servindo como reflexão para o (re) planejamento de suas aulas. 
Dessa forma, é possível percebermos que a avaliação, na maioria das vezes, é vista por esses professores como resultado final e não como parte integrante de todo o processo de ensino e aprendizagem, assumindo o caráter de verificação e medição da aprendizagem. Isso nos demonstra uma prática avaliativa tradicional em que avaliar e medir caminham juntos.

PP3: Identificar o grau de capacidade e empenho dos alunos na aquisição de conhecimento e, de certa forma, da eficiência do método de ensino aplicado.

Chaves (2003) nos chama a atenção para o fato de que "a mensuração está intimamente ligada à quantificação, ou seja, reduz o processo de avaliaçáo ao que se pode ocasionar a perda de dados importantes, que não são passíveis de ser mensurados". Infelizmente, esta visão de testagem e de mensuração ainda está impregnada na prática de muitos professores brasileiros.

Nesta visão, que classificamos de tradicional por ainda ser, a nosso ver, a que domina o processo de ensino nos dias de hoje, a avaliação de aprendizagem é encarada como um processo de "toma-lá-dá-cá”, em que o aluno deve devolver ao professor o que ele recebeu e de preferência exatamente como recebeu, o que Paulo Freire chamou de "educação bancária”. (MORETTO, 2001, p. 96)

Nesta perspectiva, a avaliação assume um papel em que levar em conta as variáveis do processo é imprescindível na organização do trabalho pedagógico, deixando de ser uma mera cobrança de conteúdos.

Os professores da área educacional compreendem como funçáo da avaliação no processo de ensino e aprendizagem o momento de acompanhar a formação de seus alunos e, consequentemente, auxiliá-los nas possíveis dificuldades. Além disso, eles acreditam que os resultados da avaliação servem para redirecionar as reflexóes relacionadas à prática docente. Concordam que, por meio da avaliação, é possível levar o aluno à reflexão sobre o tema, admitindo também uma avaliaçẫo deles sobre o professor.

PE1: São várias, talvez as mais importantes sejam: 1) Feedback para o professor do seu trabalho; 2) auxílio na formação do aluno (sendo ela formativa); 3) criar oportunidade de reflexão para o aluno sobre o seu processo.

PE2: A avaliação possui como funçóes: a) acompanhar o desenvolvimento do aluno; b) direcionar o trabalho do professor frente aos resultados obtidos com a avaliação dos educandos. 
Essa visão diferenciada dos professores da área da educação em relação ao papel da avaliaçáo nos processos formativos, tanto do aluno quanto do professor, demonstra que há uma reflexão maior nessa área de conhecimento, apesar de os professores encontrarem dificuldades para extrapolar os métodos tradicionais de avaliação.

A avaliação do aluno pelo professor passa por um posicionamento teórico-filosófico, que reflete a visão de homem que se quer formar e expressa os objetivos da educação. Sendo assim, se se almeja um processo educativo que forme indivíduos críticos e autônomos, o processo avaliativo não deve ser um apêndice do processo de formação, mas, sim, elemento integrante da atividade educativa. (CHAVES, 2003, p. 41)

São inúmeros os fatores que propiciam a prevalência das práticas avaliativas tradicionais e os professores, mesmo com as diversas demandas pedagógicas, percebem que esse tipo de avaliação náo possibilita uma formação social, política e pedagógica ao aluno. Sabemos que a inovação dessas práticas é impedida por diversos motivos, mas não podemos deixar de destacar que o professor tem um importante papel nessas mudanças, assumindo uma postura política e filosófica que inclua a avaliaçáo como protagonista no processo de ensino e aprendizagem.

A avaliaçáo da aprendizagem se coloca como aspecto preponderante, visto ser através dela e com ela, nas suas múltiplas formas (investigação, observação, provas, testes, trabalhos, exercícios etc.), que o professor terá possibilidade de acompanhar o progresso de seus alunos, refletir sobre sua prática, redimensionar e reorientar o seu trabalho em sala de aula. (CHAVES, 2003, p. 42)

Quanto à visão dos alunos sobre o papel da avaliação no processo educativo, percebemos que novamente existe uma convergência de opinióes em relação à dos professores. Isso significa que os alunos da área pura, na maioria das vezes, entenderam essa função como verificação e medição da aprendizagem. Acreditam também que é uma forma de comprovação da aquisição do conteúdo, além de uma possibilidade de melhoria para o ensino.

AP14: Garantir um bom ensino.

AP15: Testar o conhecimento do aluno.

AP5: A função das avaliaçóes é designar através de uma escala numérica (notas) a porcentagem de absorção de matéria dada em sala de aula. 
Já os alunos da área de educação entenderam a avaliação como diagnóstica (elucidando as dificuldades), como contínua (presente durante todo o processo de ensino e aprendizagem), mas especialmente como medidora/verificadora da aprendizagem.

AE17: A avaliação serve como instrumento para identificar a eficácia dos alunos.

APE20: A função da avaliação é verificar o processo de ensino exercido pelo docente.

AE14: Avaliação tem como função mostrar os resultados do processo de ensino e aprendizagem, avaliando o aluno e ao mesmo tempo a prática do professor.

Essas afirmaçóes evidenciam que tanto os alunos da área pura quanto os alunos da área educacional possuem uma visão tradicionalista sobre a avaliação da aprendizagem que consiste em uma mera verificação/medição do conhecimento. Isso se deve a uma cultura estabelecida em que a avaliação é uma forma punitiva, um recurso de repressão aos alunos, além da cultura da reprodução e repetição do conhecimento. Os alunos, nesse contexto, passam a entender a avaliação sob esses aspectos e tornam-se repetidores das suas experiências em relação às práticas avaliativas. No entanto, essa realidade deve ser transformada, sobretudo pelos discentes da licenciatura, por meio da reflexão crítica acerca do tema.

O fato de os alunos da licenciatura, em sua maioria, terem a mesma visão que os alunos do bacharelado sobre a avaliação da aprendizagem pode também ser justificado pela falta de reflexão instigada pelos professores da área educacional em suas aulas. Isso também está ligado aos instrumentos avaliativos utilizados por esses professores, além das diversas dificuldades de superarem os métodos tradicionais de ensino.

\section{Categoria 3: Instrumentos utilizados na avaliaçáo da aprendizagem}

Esta categoria de análise nos permite entender melhor quais os instrumentos avaliativos são mais recorrentes - tanto na hora de avaliar (professores) quanto na hora de ser avaliado (aluno) -, quais os ditos mais adequados para se avaliar a aprendizagem e, sobretudo, como deveria ser o processo de avaliação no Ensino Superior.

Em relação aos instrumentos mais utilizados na avaliação da aprendizagem, houve consonância entre os professores da área pura e da 
educacional apenas no item atividade em sala; houve grande divergência no emprego dos demais instrumentos.

Os professores da área pura, em sua maioria, afirmam que usam como principais instrumentos de avaliação: atividades em grupo, atividades extraclasse, debates, observação, prova escrita e seminários. Isso mostra certa variedade de instrumentos avaliativos, o que aumenta a eficácia do processo de avaliação da aprendizagem e o torna mais justo. Depresbiteris (2007) afirma que os instrumentos podem, caso sejam bem elaborados, fornecer aos professores informaçốes valiosas sobre o processo de ensino e aprendizagem. Dessa forma, é essencial diversificar os instrumentos, pois isso permite ao professor um número maior e mais variado de informaçóes e possibilita ao aluno diversas formas de expressão.

Os alunos da área pura apontam que, quando são avaliados, os instrumentos mais recorrentes são prova escrita e seminários. Rabelo (2010) reconhece que a prova escrita (individual e sem consulta) é o instrumento avaliativo mais usado ao longo da história da educação para medir a aprendizagem dos alunos, além de ser um dos principais instrumentos de controle e exclusão. Dessa forma, é preciso refletir sobre o porquê de se utilizar a prova, quais os seus benefícios e se ela pode estar a serviço da aprendizagem. Já o uso de seminários como forma de avaliação da aprendizagem estimula o debate, o trabalho em grupo, a pesquisa, a descoberta, a curiosidade, as diferentes formas de se expressar etc., sendo assim um dos instrumentos que apresenta múltiplas qualidades.

É importante destacar que, quando os alunos foram perguntados acerca de quais instrumentos avaliativos seriam os mais adequados, a prova escrita e o seminário foram os que menos apareceram. Já os professores da área educacional afirmaram não utilizar a prova escrita como principal instrumento de avaliação, dando preferência a atividades em grupo, atividades em sala de aula, debates, produçáo de texto e relatórios.

A multiplicidade de instrumentos torna a avaliação da aprendizagem mais justa e inclusiva. Muitos desses instrumentos estâo relacionados com o papel contínuo e formativo da avaliação em contraposição com a ideia de finalizaçấo do processo de ensino e aprendizagem. Os alunos da área educacional e seus professores apresentam convergência entre os instrumentos utilizados e esperados. Esse fato mostra uma grande influência dos alunos pelos professores em relação à ideia de que instrumentos para a avaliação da aprendizagem possuem mais qualidades e menos limitaçóes. 
O gráfico 1 e o 2 a seguir demonstram os instrumentos avaliativos utilizados pelos professores (reais) ao avaliar seus alunos com os instrumentos apontados pelos alunos como os mais adequados (ideais).

Gráfico: Real x Ideal [Área Pura]

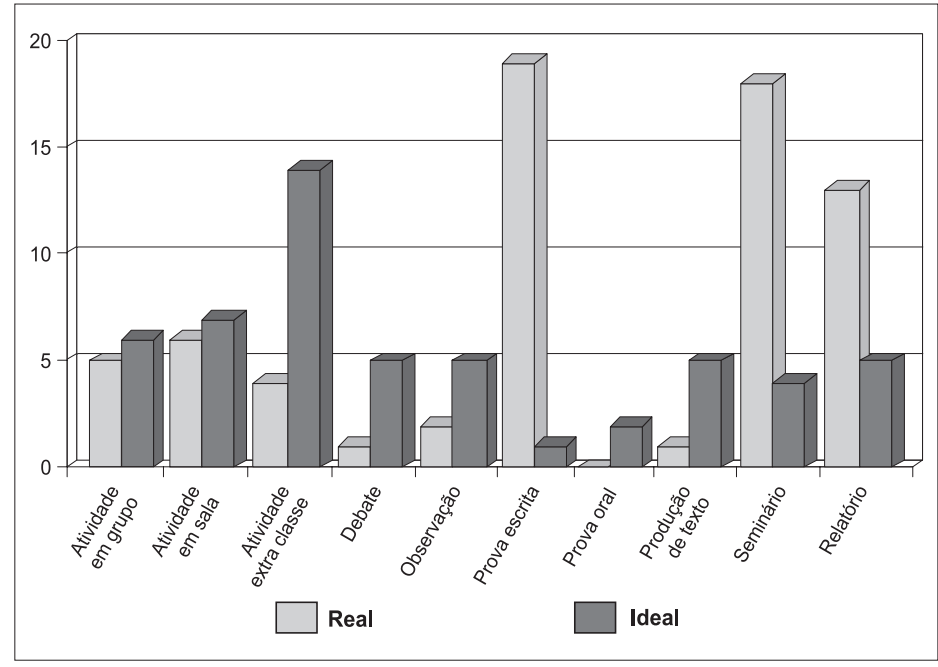

Gráfico: Real x Ideal [Área da Educação]

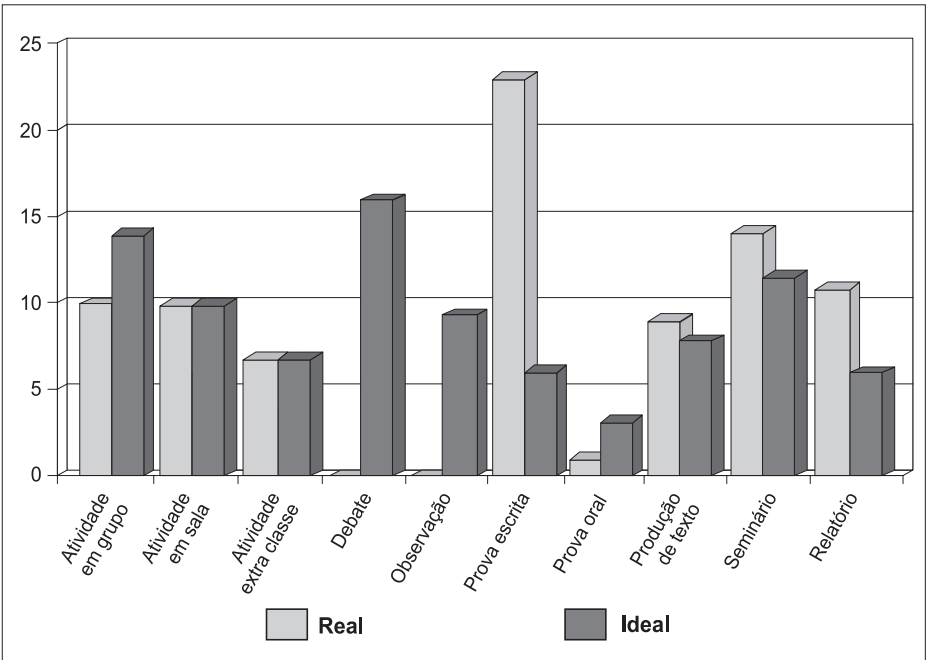


Ao analisar os dados contidos nos gráficos, notamos o quão discrepante é a realidade (instrumentos utilizados pelos professores ao avaliar seus alunos) com o ideal (o que os alunos acreditam que sejam os instrumentos avaliativos mais eficazes).

$\mathrm{O}$ fato de a prova ser o instrumento mais utilizado pelos professores, e ao mesmo tempo ser o mais criticado pelos alunos, mostra o papel excludente da prova que, na maioria das vezes, é individual e sem consulta, pontuando apenas o que o aluno náo sabe, cobrando conteúdos decorados, deixando a crítica de lado.

Essa discrepância pode implicar uma tomada de decisão dos alunos da licenciatura quando assumirem a sala de aula. Porém, a cultura da avaliação como verificação e aferição, com o uso de instrumentos tradicionais como provas escritas para medir o aprendizado, está presente durante toda a nossa vida escolar e, muitas vezes, a insatisfação não é suficiente para provocar uma mudança nas práticas avaliativas por esses futuros professores. A fala de um dos professores da área da educação elucida bem essa realidade contraditória:

PA2: A avaliação deveria ser a mais diversificada possivel e que considerasse o educando como um sujeito ativo no processo. Ainda observo no discurso dos acadêmicos (futuros professores) muitas lamentaçóes sobre os métodos avaliativos. Mas quando são apresentadas novas formas de avaliar estes oferecem certa resistência. Fica uma questão até contraditória.

Contudo, não podemos apenas reprimir certos instrumentos de avaliação e premiar outros por serem mais ou menos adequados e eficazes.

O valor da avaliação não está no instrumento em si, mas no uso que se faça dele [...] mais que o instrumento, importa o tipo de conhecimento que póe prova, o tipo de perguntas que se formula, o tipo de qualidade (mental ou prática) que se exige e as respostas que se espera obter conforme o conteúdo das perguntas ou problemas que são formulados. (MÉNDEZ, 2002, p. 98)

A reflexão que devemos fazer não está apenas em qual instrumento avaliativo empregar, mas sim em como e quando utilizá-lo e interpretá-lo. Não se deve avaliar simplesmente o que foi ensinado aos alunos. A avaliaçáo tem que se dar concomitantemente com o processo de ensino e aprendizagem, e não em um só momento específico para se avaliar. Por isso, é importante usar múltiplas ferramentas avaliativas que podem ser utilizadas em qualquer momento e não somente no fim dos bimestres e semestres. 
Em relação à avaliação da aprendizagem no Ensino Superior, os professores foram unânimes em dizer que ela náo deveria ser muito rígida nem servir apenas para gerar notas. Afirmaram também que a avaliação deveria ser reflexiva e baseada em apresentaçóes de trabalho e outras atividades em sala. No entanto, muitos professores não se esforçam para superar o modelo tradicional vigente e mudar as suas concepçóes e práticas pedagógicas relacionadas à avaliação da aprendizagem. Infelizmente o desejo de mudança, muitas vezes, fica apenas no discurso.

PP1: Apresentação de trabalhos desenvolvidos com a orientação do professor responsável.

PP2: Acredito que colocando o aluno em situaçōes de decisão e reflexão sobre um tema. Nos casos mais especificos ou na verificação do entendimento, deveriam mesmo ser provas disponibilizadas aos alunos quando eles se acham aptos a realizá-las, mas sempre sem almejar "notas".

PP3: Na minha concepção poderia ser feita com base no desempenho em sala de aula, no desenvolvimento de determinadas atividades.

Perrenoud (1999) afirma que, desde que a escola existe, pedagogos se revoltam contra as notas e querem colocar a avaliação mais a serviço do aluno do que do sistema. Essas evidências são incessantemente redescobertas, cada geraçáo que crê que "nada mais será como antes" não impede a seguinte de seguir o mesmo caminho e de sofrer desilusóes. Devemos fazer uma reflexão maior para entendermos os porquês da não mudança, da acomodação, da teoria desvinculada da prática.

\section{Consideraçóes finais}

Este artigo almejou demonstrar, em especial, as concepçóes dos professores da área pura e da área da educação sobre avaliação da aprendizagem, bem como contrapor seu discurso com suas práticas avaliativas, dando voz também aos discentes. Além disso, procuramos evidenciar os principais instrumentos utilizados no processo educativo e demonstrar qual a compreensáo desses professores e alunos sobre o papel da avaliaçáo no processo de ensino e aprendizagem.

Quanto às concepçóes sobre avaliação da aprendizagem, podemos notar uma grande discrepância entre os entrevistados (professores e alunos) da área pura e da área educacional, visto que possuem uma postura mais 
tradicional em relação ao tema e acreditam que a avaliação se resume em aferição e verificação de conhecimentos, especialmente de forma quantitativa.

Já os da área da educação apresentam uma concepção mais crítica, acreditam que a avaliação da aprendizagem é algo indissociável do processo de ensino e aprendizagem, ela é processual e contínua. Essa concepção está em consonância com vários autores que colocam em foco a avaliação como processo diagnóstico, formativo, dialógico, emancipatório, mediador, desconstruindo os modelos clássicos de avaliação (SAUL, 1988; LUCKESI, 1995; ROMÃO, 1998; HOFFMANN, 1996).

Quanto aos instrumentos avaliativos mais utilizados também temos uma grande oposição entre a área pura e a da educação, visto que os professores da área pura, na grande maioria das vezes, se utilizam do par de instrumentos prova e seminário, que estão historicamente relacionados com formas de repressão, exclusão e verificação da aprendizagem. Em contrapartida, os alunos entrevistados entendem que os instrumentos menos eficientes para a avaliação da aprendizagem são justamente provas e seminários.

Os professores da área da educação entendem que os instrumentos mais eficazes são atividades em sala feitas em grupo, debates e produçóes de texto. Acreditamos que esses instrumentos são menos rigorosos e excludentes; eles estimulam o diálogo, a liberdade de pensamento, o exercício da escrita e da fala, o que possibilita a formação crítica e emancipatória dos sujeitos envolvidos no processo.

Apesar de percebermos grande recorrência da avaliação da aprendizagem como verificação e medição de conhecimentos, notamos também que concepções mais críticas em relação ao tema, pouco a pouco, são construídas nesse universo educativo, o que demonstra um grande avanço em relação à prática pedagógica dos professores e uma formação mais crítica dos alunos. Nesse sentido, a avaliação da aprendizagem está além dos dados quantitativos e classificatórios, levando-se em consideração a multiplicidade de motivos que contribuem para o fornecimento de informaçóes sobre o processo de aprendizagem e as dificuldades vivenciadas pelos alunos.

\section{Referências}

ANDRADE, P. F. de. Avaliação da aprendizagem. Site \& Insight, Taguatinga, v. 1, n. 1, p. 41-55, jul./dez., 2003. 
CARVAlHO, G. G. de. Amostragem na pesquisa qualitativa. 2006. Disponível em: <http://designinterativo.blogspot.com.br/2006/08/ amostragem-na-pesquisa-qualitativa.html>. Acesso em: nov. 2010.

CHAVES, S. M. Avaliação da aprendizagem no Ensino Superior: realidade, complexidade e possibilidades. Tese (Doutorado em Educação) Universidade Federal de São Paulo, São Paulo, 2003.

DALBEN, A. I. L. de Freitas. Das avaliaçóes exigidas às avaliaçóes necessárias. In: VILLAS BOAS, B. M. de F. (Org.). Avaliação: políticas e práticas. 3. ed. Campinas: Papirus, 2002.

DIPRESBITERIS, L. Instrumentos de avaliação: a necessidade de conjugar técnicas e procedimentos éticos. Revista Aprendizagem. Pinhais: Editora Melo, ano 1, n. 1, jul./ago., 2007.

FRASER, M. T. D.; GONDIM, S. M. G. Da fala do outro ao texto negociado: discussóes sobre a entrevista na pesquisa qualitativa. São Paulo: Paideia, 2004.

HOFFMANN, J. Avaliação mediadora. Uma prática em construção da préescola à universidade. Porto Alegre: Medicação, 1996.

LUCKESI, C. C. Avaliação da aprendizagem escolar. São Paulo: Cortez, 1995.

MÉNDEZ, J. M. A. Avaliar para conhecer, examinar para excluir. Porto Alegre: Artmed, 2002.

MINAYO, Maria Cecília de Souza (Org.). Pesquisa social: teoria, método e criatividade. 14. ed. Petrópolis, RJ: Vozes, 1999.

MORETTO, Vasco Pedro. Prova: um momento privilegiado de estudo e não um

acerto de contas. 3. ed. Rio de Janeiro: DP\&A, 2001.

NEVES, J. L. Pesquisa qualitativa: características, usos e possibilidades. Cadernos de Pesquisas em Administração. São Paulo, v. 1, n. 3, 20 sem. 1996.

PERRENOUD, P. Avaliação: da excelência à regulação das aprendizagens. Entre duas lógicas. Tradução de Patrícia C. Ramos. Porto Alegre: Artmed, 1999. 
RABELO, K. S. de P. Ensino de Geografia e avaliação formativa da aprendizagem: experiências e princípios na Rede Pública de Goiânia, GO. Dissertação (Mestrado em Geografia) - Universidade Federal de Goiás, Goiânia, 2010.

ROMÃO, J. E. Avaliação dialógica: desafios e perspectivas. São Paulo: Cortez, 1998. (Guia da Escola Cidadã, v. 2).

SAUL, A. M. Avaliação emancipatória. São Paulo: Cortez, 1988.

YAREMKO, R. K.; HARARI, H.; HARRISON, R. C.; LYNN, E. Handbook of research and quantitative methods in psycology. Hillssdale, NJ: Lawrence Erlbaum, 1986.

Recebido em: 30 maio 2012

Aceito em: 16 out. 2012 